(c) American Dairy Science Association, 2005.

\title{
Description of Herd Level Criteria for Good and Poor Udder Health in Norwegian Dairy Cows
}

\author{
J. P. Valde, ${ }^{1}$ O. Østerås, ${ }^{1,2}$ and E. Simensen ${ }^{1}$ \\ ${ }^{1}$ Department of Production Animal Medicine, \\ The Norwegian School of Veterinary Science, \\ $\mathrm{N}-0033$ Oslo, Norway \\ ${ }^{2}$ TINE Norwegian Dairies, N-1431 Ås, Norway
}

\begin{abstract}
Data from the Norwegian dairy herd recording system were used to evaluate herd level criteria for good and poor udder health in dairy cows. All dairy herds with at least 10 cow-years were included $(n=12,780)$. The association between bulk milk somatic cell count (BMSCC) and clinical mastitis rate $(\mathrm{CM})$ was weak $\left(\mathrm{R}^{2}=0.002\right)$, indicating that studies based on BMSCC provide different information regarding udder health than studies based on CM. The strongest correlations were found between average cow milk somatic cell count (CMSCC) and BMSCC and between percentage of individual cow milk sample $>200,000$ cells $/ \mathrm{mL}$ and the variables BMSCC and CMSCC. A new variable called new infection rate (NEWINF) based on individual cow somatic cell count measurements and CM was evaluated. The NEWINF is influenced by the frequency of individual cow milk samplings, and, to compare herds, it is necessary to adjust for the frequency of cow milk samplings on each farm. The NEWINF was found to be a useful tool for describing overall udder health status at the farm level, as it combines both CM and somatic cell count.
\end{abstract}

(Key words: udder health, new infection rate of mastitis, somatic cell count, clinical mastitis)

Abbreviation key: ADJ-NEWINF = adjusted new infection rate of mastitis, BMSCC = bulk milk somatic cell count, $\mathbf{C M}=$ clinical mastitis rate, $\mathbf{C M S C C}=$ weighted mean cow milk (composite) somatic cell count, DELIVERY\% = percentage delivered milk, DHRS = dairy herd recording system, M-DURATION = mean duration of mastitis, NEWINF = new infection rate of mastitis, N-SAMPLING = number of milk samplings, PORTION200 $=$ percentage of individual cow milk samples $>200,000$ cells $/ \mathrm{mL}$.

Received February 10, 2004.

Accepted August 19, 2004

Corresponding author: J. P. Valde; e-mail: jpvalde@online.no.

\section{INTRODUCTION}

Evaluation of farm level udder health status by means of relevant criteria is of great importance for selecting dairy herds that should be offered a mastitis prevention program and classifying herds according to udder health status for research purposes. The preferred criteria have changed as new methods have been developed. Estimation of average bulk milk somatic cell count (BMSCC) in addition to reported cases of clinical mastitis (CM) are the most commonly used criteria for distinguishing between herds with good and poor udder health status (Schukken et al., 1989; Schukken et al., 1990; Emanuelson and Funke, 1991; Barkema et al., 1998b; Barkema et al., 1999). The BMSCC is part of the milk quality control program and is thus easily available for research purposes; a number of studies based on BMSCC have been carried out (Østerås and Lund, 1988; Goodger et al., 1993; Fenlon et al., 1995; Wilson et al., 1997; Barkema et al., 1998a; Khaitsa et al., 2000). In addition, studies have been conducted on the percentage of cows with SCC above a certain limit (Hutton et al., 1990). In recent years, other factors have been introduced to either replace or supplement BMSCC and CM as criteria for udder health status at the farm level.

Studies have demonstrated that elevated BMSCC and increased CM have been caused by different environmental risk factors (Østerås and Lund 1988; Schukken et al., 1989, 1990) simply because BMSCC and CM are 2 different parameters describing farm level udder health status. Udder health status for individual cows during lactation has been defined on the basis of several characteristics. One study chose to identify each cow by an udder health profile including 5 characteristics related to mastitis (Faye et al., 1998). As is the case for udder health status at the cow level, no single variable is probably able to fully describe average udder health status at the herd level.

The purpose of the present study was to describe the correlation amongst different herd level mastitis variables and discuss their strengths and weaknesses as criteria for good and poor udder health. 


\section{MATERIALS AND METHODS}

Data from the Norwegian dairy herd recording system (DHRS) was used for the analyses. This system requires that dairy farmers collect individual (composite) milk samples from all lactating cows at least every second month. Disease treatments are recorded on individual health cards, and the data are reported periodically to the central database. All herds with at least 10 cow-years that met the criteria for reporting to the system were included in the study. The core period studied was from January 1, 1998 through December 31, 1998.

\section{Mastitis Variables}

The following variables were used to describe udder health status in each herd.

New infection rate (NEWINF) was the number of new infections per 100 cows sampled, based on milk control samples during 1998. New infection was defined as a conversion of individual (composite) SCC from below to $>200,000$ cells $/ \mathrm{mL}$ or an event of mastitis treatment if the previous SCC for the particular cow was $<200,000$ cells $/ \mathrm{mL}$. The calculation of NEWINF included changes in SCC between the last test before dry off and the first test after recalving. Somatic cell count $>200,000$ cells $/ \mathrm{mL}$ in the first test of heifers was counted as a new infection. Since 1995, NEWINF has been routinely calculated by the DHRS and reported regularly to the milk producers.

Adjusted new infection rate (ADJ-NEWINF) was the NEWINF adjusted for the frequency of cow milk samplings during 1998.

Percentage of individual cow milk samples $>200,000$ cells/mL (PORTION200), calculated as the number of samples with SCC $>200,000$ cells $/ \mathrm{mL}$ during 1998 divided by the total number of samples $\times 100$, was used as a measure of the mean udder infection level in the herd. The level of 200,000 was chosen in accordance with a study by Dohoo and Leslie (1991).

Mean duration of mastitis (M-DURATION) was the average time in months from first detection of a new infection until SCC again was recorded to be $<200,000$ cells $/ \mathrm{mL}$. The M-DURATION was calculated as PORTION200 divided by NEWINF $\times 100$, in accordance with Dodd (1980). The percentage found was then converted to months.

Clinical mastitis rate was defined as number of reported cases of CM per 100 cow-years during 1998.

Weighted mean BMSCC was based on the bulk milk samples collected by the dairy trucker twice a month. The BMSCC was calculated as the arithmetic mean of all samples weighted by milk amount on the day of sampling.
Weighted mean cow milk (composite) SCC (CMSCC) was the arithmetic mean of all individual cow SCC measurements during 1998 weighted by each cow's 24$\mathrm{h}$ milk production on the day of sampling.

Percentage delivered milk (DELIVERY\%) was the total amount of milk delivered to the dairy industry in 1998 divided by produced milk $\times 100$. Produced milk was estimated from each cow's 24 -h milk production, which was measured once a month during lactation and reported to the DHRS. Not delivered milk is mainly due to milk fed to calves and discarded milk because of medical residues.

Culling rate because of mastitis was the number of cows culled because of mastitis or teat injury per 100 cow-years during 1998. The reason for culling was given by the farmer in the individual cases.

Total culling rate was the total number of cows culled per 100 cow-years during 1998.

\section{Statistical Methods}

All calculations were performed by SAS/STAT (PROC MEANS, PROC REG, PROC CORR; SAS, 1990). The relationship between NEWINF and number of milk samplings (N-SAMPLING) was measured by modeling NEWINF on N-SAMPLING and N-SAMPLING squared by all-possible-regressions procedure for model reduction. Backward elimination procedure based on adjusted $\mathrm{R}^{2}$ and Mallow's Cp was used to fit the model (Kleinbaum et al., 1987). The result from the final model was applied to calculate ADJ-NEWINF.

\section{RESULTS}

Of a total of 20,431 herds in the database, 12,780 were included. Of these, 29\% (5885 herds) were excluded because they had $<10$ cow-years. Of those remaining, $12 \%$ (1766 herds) were excluded because they did not meet the criteria of collecting (composite) milk samples from all lactating cows at least 5 times during the year. Mean herd size was 15.7 cow-years for all herds included in the statistical analyses.

Figure 1 shows the frequency distribution of milk samplings, indicating that $93 \%$ of farmers collected individual milk samples 5,6 , or 7 times during the year. Only $1.3 \%$ of the farmers collected individual cow milk samples every month.

Descriptive statistics for herd mastitis variables are given in Table 1. Mean (unadjusted) NEWINF for all herds was 57.5 new infections per 100 cows sampled, which was not statistically different from ADJ-NEW$\operatorname{INF}(P=0.94)$.

Although mean CM was approximately 36 reported cases per 100 cow-years, $7.2 \%$ of the farmers did not report a single case of CM in 1998. 


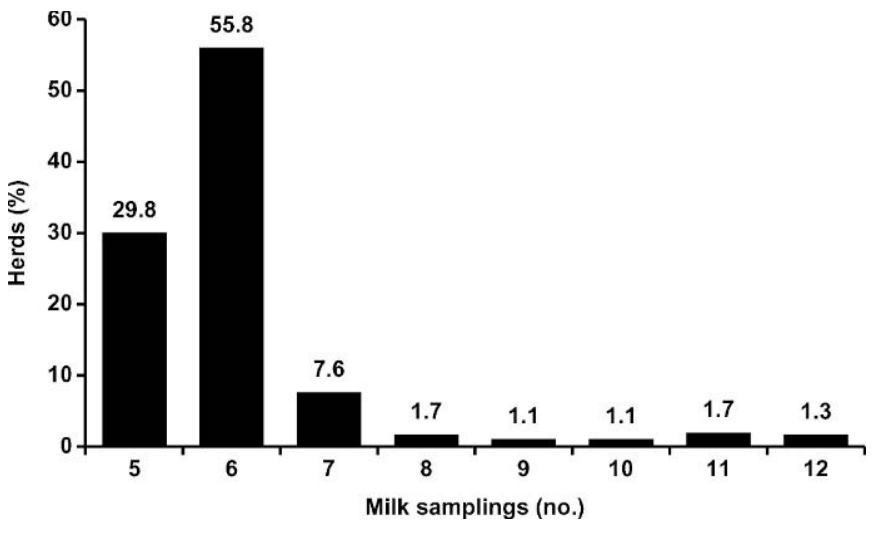

Figure 1. Distribution of the frequency of milk samplings among Norwegian dairy herds in 1998.

Pearson correlation coefficient and $P$ values for different mastitis variables are given in Table 2. Except for NEWINF and ADJ-NEWINF, which were calculated from the same measurements, the strongest correlations were found between CMSCC and BMSCC and between PORTION200 and the variables BMSCC and CMSCC. The correlation coefficient between $\mathrm{CM}$ and BMSCC was relatively small.

The scatter plot of CM on BMSCC in Figure 2 shows that the association between these 2 variables was weak $\left(R^{2}=0.002\right)$. Herds in the first (lower) quartile with respect to $\mathrm{CM}$ were almost evenly distributed according to the BMSCC quartiles. Among herds in the first quartile with respect to CM, 27, 24, 23, and $26 \%$ of the herds were in the first, second, third, and fourth quartile with respect to BMSCC, respectively. Only the fourth quartile of $\mathrm{CM}$ was significantly different from the others with respect to mean BMSCC at a level of significance of 0.01 over all comparisons ( $\mathrm{n}=12,780$ ).
Mean BMSCC was $148,145,147$, and $152 \times 1000$ cells/ $\mathrm{mL}$ in the first, second, third, and fourth quartile of CM, respectively.

The distribution of NEWINF was approximately normal, with skewness and kurtosis of 0.53 and 0.78 , respectively (Figure 3 ). The NEWINF could be $>100 \%$ because multiple cases of CM could be reported for an individual cow between consecutive test days. The NEWINF was found to be influenced by the farmer's frequency of individual cow milk samplings according to the following final regression model:

$$
\begin{gathered}
\text { NEWINF }=19.948+7.28 \times \mathrm{N}^{-S A M P L I N G} \\
-0.17 \times \mathrm{N}^{-S A M P L I N G}{ }^{2}
\end{gathered}
$$

where N-SAMPLING = number of milk samplings in $1998\left(\mathrm{R}^{2}=0.085, P<0.001\right)$.

Thus, for each increase in the number of times the cows were sampled during the year, mean NEWINF increased somewhere between 3 and 5 units, depending on the level of milk sampling frequency (Figure 4). The calculations showed that the NEWINF increased from an average of 57.3 new infections per 100 cows in herds where individual milk samples were collected 6 times/ yr (every second month) to 83.7 for herds with individual milk samplings 12 times/yr.

The scatter plot of NEWINF on CMSCC at the herd level shows that NEWINF increased with increased CMSCC up to a certain level. Above approximately 300,000 cells $/ \mathrm{mL}$, almost no correlation was found (Figure 5).

To compare herds with different frequencies of individual cow milk samplings, ADJ-NEWINF was calculated. With 6 times regarded as the reference level, ADJ-NEWINF was calculated by use of the following formula based on the previous model:

Table 1. Descriptive statistics for mastitis variables measured in Norwegian dairy herds with at least 10

\begin{tabular}{|c|c|c|c|c|}
\hline Mastitis variable & $\begin{array}{l}\text { Herds } \\
\text { (no.) }\end{array}$ & Mean/median & SD & Range \\
\hline New infection rate (cases per 100 cows sampled) & 12,780 & $57.5 / 56.0$ & 20.1 & $0.0-208.0$ \\
\hline Adjusted new infection rate (cases per 100 cows sampled) & 12,780 & $57.5 / 56.0$ & 19.2 & $-6.2-208.0$ \\
\hline Percentage individual sample $>200,000$ cells $/ \mathrm{mL}$ & 12,780 & $20.9 / 20.0$ & 9.3 & $0.0-67.0$ \\
\hline Mean duration of mastitis in months & 12,762 & $4.1 / 3.9$ & 1.5 & $0.3-13.4$ \\
\hline Clinical mastitis (cases per 100 cow-years) & 12,780 & $36.0 / 31.0$ & 27.4 & $0.0-270.0$ \\
\hline BMSCC $^{1}(\times 1000$ cells/mL. $)$ & 12,777 & $148.1 / 141.0$ & 54.2 & $23.0-489.0$ \\
\hline CMSCC $^{2}(\times 1000$ cells/mL. $)$ & 12,780 & $169.4 / 156.9$ & 74.4 & $25.6-729.0$ \\
\hline Percentage delivered milk & $12,694^{\mathrm{a}}$ & $87.6 / 88.1$ & 6.1 & $50.8-109.8$ \\
\hline Culling rate because of mastitis (cows per 100 cow-years) & 12,780 & $7.6 / 6.0$ & 9.4 & $0.0-98.0$ \\
\hline Total culling rate (cows per 100 cow-years) & 12,780 & $44.3 / 43.0$ & 18.3 & $0.0-262.0$ \\
\hline Number of cow-years & 12,780 & $15.7 / 14.2$ & 5.9 & $10.0-121.3$ \\
\hline
\end{tabular}
cow-years. Data from the Norwegian dairy herd recording system for 1998.

${ }^{\mathrm{a}} \mathrm{A}$ total of 86 herds were excluded because of extreme values $(\leq 50$ and $\geq 110)$.

${ }^{1}$ BMSCC $=$ Bulk milk SCC.

${ }^{2}$ CMSCC $=$ Weighted mean cow milk (composite) SCC. 
Table 2. Pearson correlation coefficients and $P$ values $\left(\mathrm{H}^{0}\right.$ : coefficient $\left.=0\right)$ for different mastitis variables in herds with $\geq 10$ cow-years. Data from the Norwegian dairy herd recording system for 1998.

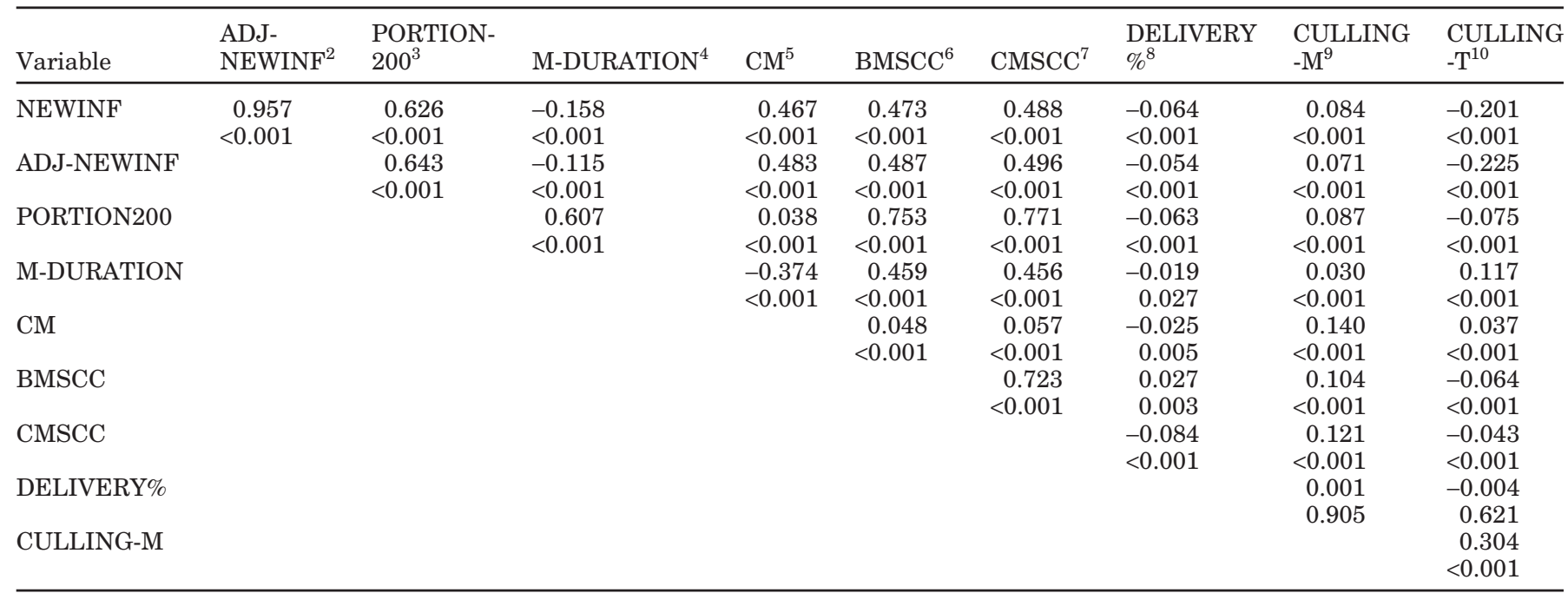

${ }^{1} \mathrm{NEWINF}=$ New infection rate of mastitis.

${ }^{2} \mathrm{ADJ}-\mathrm{NEWINF}=$ Adjusted new infection rate of mastitis.

${ }^{3}$ PORTION200 $=$ Percentage of individual cow milk samples $>200,000$ cells $/ \mathrm{mL}$.

${ }^{4} \mathrm{M}$-DURATION = Mean duration of mastitis.

${ }^{5} \mathrm{CM}=$ Clinical mastitis rate.

${ }^{6}$ BMSCC $=$ Bulk milk SCC.

${ }^{7} \mathrm{CMSCC}=$ Weighted mean cow milk (composite) SCC.

${ }^{8}$ DELIVERY\% = Percentage of delivered milk.

${ }^{9}$ CULLING-M $=$ Culling rate because of mastitis.

${ }^{10} \mathrm{CULLING}-\mathrm{T}=$ Total culling rate.

\section{ADJ-NEWINF $=$ NEWINF $-7.28 \times$ N-SAMPLING $+0.17 \times$ N-SAMPLING ${ }^{2}+37.54$.}

Figure 6 shows that when adjusting for the frequency of milk samplings, the influence of the number of sam-

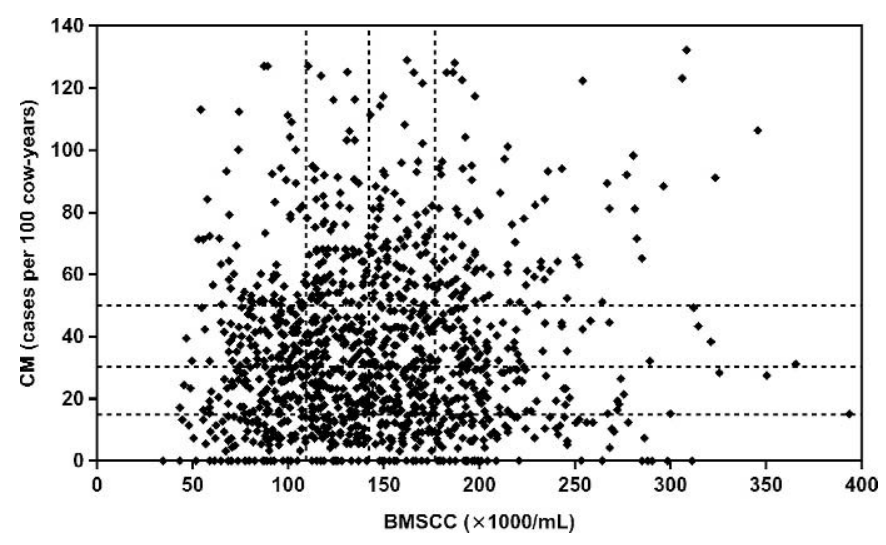

Figure 2. Simple linear regression and plots of mean bulk milk SCC (BMSCC) vs. clinical mastitis (CM) rate for a random sample of $10 \%$ of the herds $(n=1278)$ included in the study. Dotted lines mark the different quartiles of CM and BMSCC. Data were from the Norwegian dairy herd recording system for 1998. plings was eliminated. There were no significant differences in ADJ-NEWINF between herds grouped according to number of milk samplings ( $P=0.793 ; F$-test).

Mean BMSCC was calculated to be 146,700 cells $/ \mathrm{mL}$ for herds with 6 milk samplings a year, which was not statistically different from 145,000 cells $/ \mathrm{mL}$ for herds with 12 samplings/yr. Corresponding values for $\mathrm{CM}$

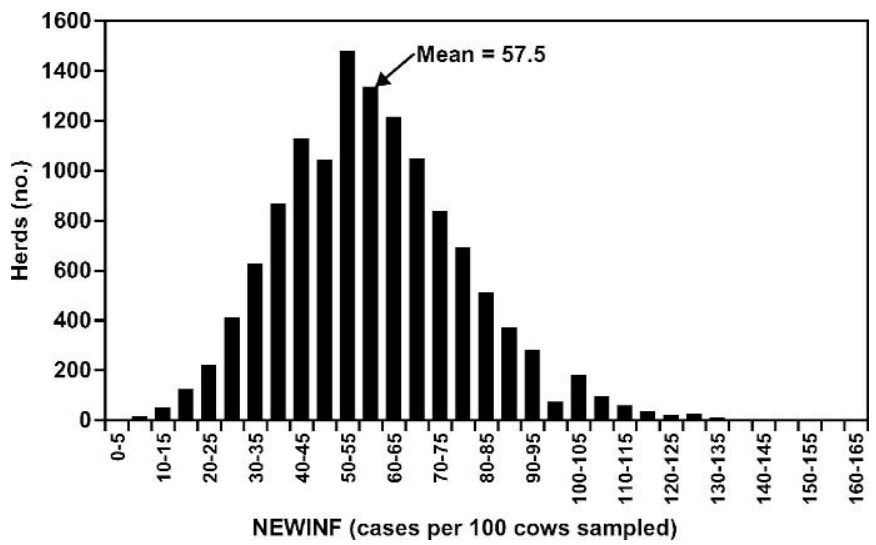

Figure 3. Distribution of new infection rate of mastitis (NEWINF) in 1998 among Norwegian dairy herds with at least 10 cow-years. 


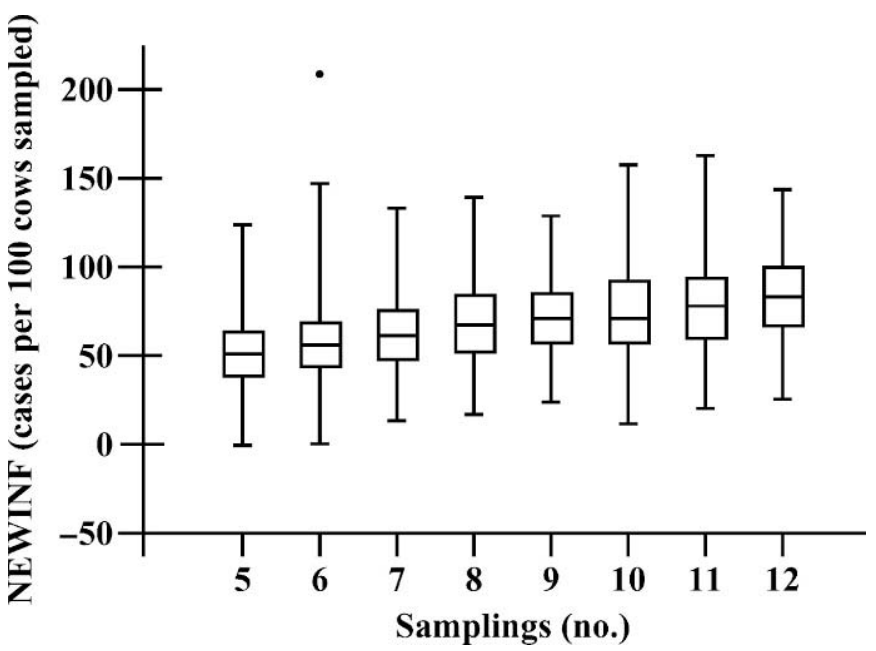

Figure 4. Box plots of new infection rate of mastitis (NEWINF) by number of individual milk samplings in 1998. Data were from the Norwegian dairy herd recording system for 1998.

were 36.2 and 36.1 reported cases of clinical mastitis per 100 cow-years, respectively.

On the other hand, M-DURATION was calculated to be 2.9 mo in herds where individual (composite) milk samples were analyzed 12 times, compared with 4.1 in herds where milk samples were analyzed 6 times/yr.

\section{DISCUSSION}

Only herds with at least 10 cow-years were included in the study, which increased the average herd size to 15.7 cow-years compared with 13.3 cow-years for the entire population in the database. Herds with $<10$ cowyears were excluded because mastitis estimates in these herds are more likely to be inaccurate.

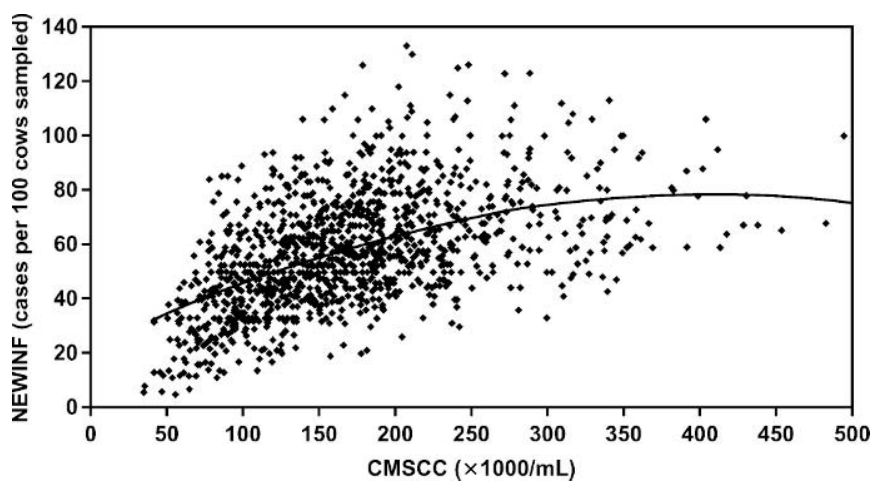

Figure 5. Regression line and plots of mean cow milk SCC (CMSCC) vs. new infection rate of mastitis (NEWINF) for a random sample of $10 \%$ of the herds $(n=1278)$ included in the study. Data were from the Norwegian dairy herd recording system for 1998.

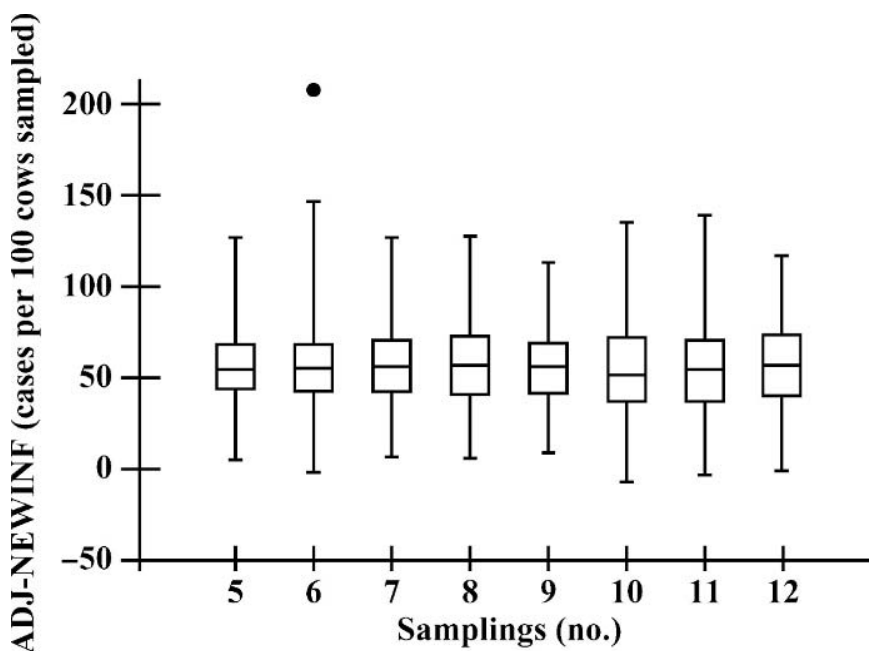

Figure 6. Box plots of adjusted new infection rate of mastitis (ADJ-NEWINF) by number of individual milk samplings in 1998. Data were from the Norwegian dairy herd recording system for 1998.

In most countries, individual cow SCC measurements are usually an integral part of milk recording. Information on individual cow SCC is useful to ensure that only high quality milk is offered to consumers. Because of the quality payment scheme and production quotas, most farmers avoid delivering milk from high-cell-count cows to the dairy industry. Table 2 shows that DELIVERY\% was negatively correlated with all mastitis parameters except for BMSCC, which indicated that some herds with poor udder health had a higher proportion of milk that was not delivered than herds with good udder health status. When farmers discarded high-cellcount milk (thus lowering the DELIVERY\%), BMSCC decreased. The data also showed that CMSCC explained more of the between-herd variability in DELIVERY\% than did CM $(r=-0.084$ and $r=-0.025$, respectively). This indicates that some farmers withheld milk from cows whose udder health was questionable, even though they did not treat the cows for CM. Hence, BMSCC would be lower than the average CMSCC in those herds.

As farmers have different treatment strategies for mastitis, some of the difference in CM between herds may reflect different management practices rather than true differences in mastitis incidence rates. Without treatment by a veterinarian, cases of mastitis will most often not be reported to the DHRS, and the milk that has been withheld will be fed to calves or discarded. Thus, CM will be underestimated, especially in highcell-count herds.

The NEWINF was calculated as the annual incidence rate of new infections, where new infection was either a new case of mastitis or an event of elevated individual 
SCC from $<200,000$ to $>200,000$ cells $/ \mathrm{mL}$. The denominator was the total number of cows sampled $\times 100$. This was an approximation for practical purposes, as NEWINF did not take into account the fact that some cows were not at risk all the time. To compare herds, it is necessary to adjust for the frequency of individual SCC samplings, as NEWINF was influenced by the number of individual cow SCC measurements during the year. Six times was chosen as the baseline level, as most farmers collect individual milk samples for SCC measurements every second month, in agreement with the standard included in the surveillance program recommended by the DHRS (additional cell count analyses are available on request at extra cost). To ensure a more accurate estimate of NEWINF and to keep up with the changes in individual udder health status over time, 12 regular samplings/yr should be recommended.

The relevance of using NEWINF in large herds is limited because of the high cost of extended SCC measurements. However, NEWINF may be useful during periods of extended monitoring or if applied to a selected group of cows.

The correlation to CM, BMSCC, and CMSCC was slightly stronger for ADJ-NEWINF than for NEWINF (Table 2), indicating that NEWINF might be overestimated in herds with frequent sampling or underestimated if the frequency of individual milk samplings is low. The correlation between NEWINF and the number of individual cow SCC measurements is obvious, as the probability of detecting a disease is higher the more we look for it. NEWINF could also be biased because farmers having udder health problems in their herds have a greater need for individual cow SCC measurements and thus collect milk samples more frequently than farmers with healthy herds. However, this appeared to be true for only a small minority of the farmers, as a mere $1.3 \%$ of those included in the study requested individual cow SCC measurements every month during the year (Figure 1). In addition, our calculations revealed that neither BMSCC nor CM was significantly higher among herds where individual milk samples were analyzed for SCC 12 times compared with 6 times/yr. Because neither BMSCC nor CM was influenced by the number of milk samplings, high levels of BMSCC or high CM could not be the main reason for a farmer to use increased monitoring by means of more frequent individual milk samplings.

The NEWINF was not statistically different from ADJ-NEWINF. Because the difference in NEWINF between herds from which individual (composite) milk samples were collected 12 times and herds sampled only 6 times was relatively large, greater difference might have been expected. The reason for the very small difference between NEWINF and ADJ-NEWINF was that not $>6.9 \%$ of the farmers collected individual milk samples $>7$ times during the year, thus contributing only slightly to the average.

Figure 5 shows that the correlation between CMSCC and NEWINF was not linear. The NEWINF increased with increasing CMSCC up to about 300,000 cells $/ \mathrm{mL}$, but for high SCC herds, the correlation was weak. This indicated that while NEWINF was a useful parameter for between-herd variability among herds with average CMSCC $<300,000$ cells $/ \mathrm{mL}$, it was not able to grade the level of udder infections among herds with CMSCC $>300,000$ cells $/ \mathrm{mL}$.

Culling rate because of mastitis depends largely on what the farmers state as their reason for culling. They can choose between different reasons for the same cow (e.g., mastitis, ketosis, hoof problems, milk fever, low milk yield, low breeding value) and which one they select may be random. Thus, the culling rate caused by mastitis is not a good variable to use when comparing herds' udder health. The fact that the correlations between this and the other variables were weak (Table 2) confirms this observation. Culling rate because of mastitis was also found not to be statistically different among herds with high, middle, or low BMSCC in another study (Barkema et al., 1998b).

The variable M-DURATION was a measure of the mean length of the period a cow had a cell count $>200,000$ cells $/ \mathrm{mL}$. The frequency of milk samplings had the opposite effect on M-DURATION as compared with NEWINF, because some udder inflammations of short duration would not be identified with infrequent sampling. This finding also supports the call for standard monthly measurements of individual SCC.

In this study, different criteria have been used to classify herds according to udder health status. It is important to know that studies based on BMSCC as a criterion for udder health status are not necessarily comparable with studies based on CM or other criteria, and both types could be strongly biased by differences in the farmer's management practices. Furthermore, classification of herds according to calculated averages for $\geq 3$ subsequent yr is more accurate, and herds are less likely to be misclassified as either case or control herds (Dohoo and Leslie, 1991; Goodger et al., 1993).

Udder health can be described by a variety of variables, each of them providing different information. The correlation between the classic parameters CM and BMSCC is low, whereas NEWINF is highly correlated with both and thus appears to be a useful overall tool for describing udder health status at the group level.

\section{ACKNOWLEDGMENT}

This research was funded by the Norwegian Research Council and TINE Norwegian Dairies. The access to 
the data was given by the Norwegian DHRS and the Norwegian Cattle Health Services (for health data) in agreement number 4/1998.

\section{REFERENCES}

Barkema, H. W., Y. H. Schukken, T. J. Lam, M. L. Beiboer, G. Benedictus, and A. Brand. 1998a. Management practices associated with low, medium, and high somatic cell counts in bulk milk. J. Dairy Sci. 81:1917-1927.

Barkema, H. W., Y. H. Schukken, T. J. Lam, M. L. Beiboer, H. Wilmink, G. Benedictus, and A. Brand. 1998b. Incidence of clinical mastitis in dairy herds grouped in three categories by bulk milk somatic cell count. J. Dairy Sci. 81:411-419.

Barkema, H. W., J. D. van der Ploeg, Y. H. Schukken, T. J. Lam, G. Benedictus, and A. Brand. 1999. Management style and its association with bulk milk somatic cell count and incidence rate of clinical mastitis. J. Dairy Sci. 82:1655-1663.

Dodd, F. H. 1980. Mastitis control. Pages 11-23 in Mastitis Control and Herd Management. A. J. Bramley, F. H. Dodd, and T. K. Griffin, ed. Technical Bulletin 4. National Institute for Research in Dairying, Reading, UK.

Dohoo, I. R., and K. E. Leslie. 1991. Evaluation of changes in somatic cell counts as indicators of new intramammary infections. Prev. Vet. Med. 10:225-237.

Emanuelson, U., and H. Funke. 1991. Effect of milk yield on relationship between bulk milk somatic cell count and prevalence of mastitis. J. Dairy Sci. 74:2479-2483.

Faye, B., L. Perochon, N. Dorr, and P. Gasqui. 1998. Relationship between individual-cow udder health status in early lactation and dairy cow characteristics in Brittany, France. Vet. Res. 29:31-46.

Fenlon, D. R., D. N. Logue, J. Gunn, and J. Wilson. 1995. A study of mastitis bacteria and herd management practices to identify their relationship to high somatic cell counts in bulk tank milk. Br. Vet. J. 151:17-25.

Goodger, W. J., T. Farver, J. Pelletier, P. Johnson, G. de Snayer, and J. Galland. 1993. The association of milking management practices with bulk tank somatic cell counts. Prev. Vet. Med. 15:235-251.

Hutton, C. T., L. K. Fox, and D. D. Hancock. 1990. Mastitis control practices: Differences between herds with high and low milk somatic cell counts. J. Dairy Sci. 73:1135-1143.

Khaitsa, M. L., T. E. Wittum, K. L. Smith, J. L. Henderson, and K. H. Hoblet. 2000. Herd characteristics and management practices associated with bulk-tank somatic cell counts in herds in official Dairy Herd Improvement Association programs in Ohio. Am. J. Vet. Res. 61:1092-1098.

Kleinbaum, D. G., L. L. Kupper, and K. E. Muller. 1987. Pages 318 326 in Applied Regression Analysis and Other Multivariable Methods. 2nd ed. Duxbury Press, Belmont, CA.

Østerås, O., and A. Lund. 1988. Epidemiological analysis of the associations between bovine udder health and housing. Prev. Vet. Med. 6:79-90.

SAS/STAT User's Guide, Version 6. 1990. SAS Inst., Inc., Cary, NC.

Schukken, Y. H., F. J. Grommers, D. Van de Geer, H. N. Erb, and A. Brand. 1990. Risk factors for clinical mastitis in herds with a low bulk milk somatic cell count. 1. Data and risk factors for all cases. J. Dairy Sci. 73:3463-3471.

Schukken, Y. H., D. Van de Geer, F. J. Grommers, J. A. H. Smit, and A. Brand. 1989. Intramammary infections and risk factors for clinical mastitis in herds with low somatic cell counts in bulk milk. Vet. Rec. 125:393-396.

Wilson, D. J., H. H. Das, R. N. Gonzalez, and P. M. Sears. 1997. Association between management practices, dairy herd characteristics, and somatic cell count of bulk tank milk. JAVMA 210:1499-1502. 